\title{
High prevalence of early asymptomatic venous thromboembolism in anticoagulated COVID-19 patients hospitalized in general wards
}

\author{
Sylvain Le Jeune ${ }^{1} \cdot$ Jaehyo Suhl ${ }^{1} \cdot$ Ruben Benainous $^{1} \cdot$ François Minvielle $^{2} \cdot$ Christine Purser $^{2} \cdot$ Farid Foudi $^{1}$. \\ Ursula Warzocha ${ }^{1} \cdot$ Robin Dhote $^{1}$
}

Published online: 18 August 2020

(c) Springer Science+Business Media, LLC, part of Springer Nature 2020

\begin{abstract}
Coronavirus disease 2019 (COVID-19) is associated with coagulation activation and high incidence of venous thromboembolism (VTE) in severe patients despite routine thromboprophylaxis. Conflicting results exist regarding the epidemiology of VTE for unselected anticoagulated COVID-19 patients hospitalized in general wards. The aim of this study was to evaluate the prevalence of asymptomatic deep venous thrombosis (DVT) in unselected patients with COVID-19 recently hospitalized in general wards. We performed a systematic complete doppler ultrasound (CDU) at a median 4 days after admission in 42 consecutive COVID-19 patients hospitalized in general wards of our university hospital, irrespective of D-Dimer level, and retrospectively collected clinical, biological and outcome data from electronic charts. Thromboprophylaxis was systematically applied following a French national proposal. In our population, the prevalence of asymptomatic DVT was 19\% (8/42 patients), with distal thrombosis in 7/8 cases and bilateral DVT in 4/8 cases. Symptomatic pulmonary embolism was detected in $4(9.5 \%)$ patients, associated to DVT in one case. Compared to patients without DVT, patients with DVT were older and experienced poorer outcomes. In conclusion, prevalence of asymptomatic DVT is high in the first days of hospitalization of unselected COVID-19 patients in general wards and may be related to poor prognosis. Individualized assessment of thromboprophylaxis and early systematic screening for DVT is warranted in this context.
\end{abstract}

Keywords SARS-CoV-2 $\cdot$ COVID-19 $\cdot$ Anticoagulation $\cdot$ Venous thromboembolism $\cdot$ General wards

\section{Highlights}

- COVID-19 is associated with high incidence of venous thromboembolism (VTE) despite prophylaxis.

- True prevalence of VTE in anticoagulated COVID-19 patients in general wards is unknown.

Electronic supplementary material The online version of this article (https://doi.org/10.1007/s11239-020-02246-w) contains supplementary material, which is available to authorized users.

Sylvain Le Jeune

sylvain.le-jeune@aphp.fr

1 Service de Médecine Interne, Centre Hospitalo-Universitaire Avicenne, Assistance Publique-Hôpitaux de Paris, 125 rue de Stalingrad, 93000 Bobigny, France

2 Service des Explorations Fonctionnelles, Centre Hospitalo-Universitaire Avicenne, Assistance Publique-Hôpitaux de Paris, Bobigny, France
- Using early screening, we found $19 \%$ of asymptomatic VTE in a retrospective cohort of 42 patients.

- Individualized prophylaxis and early systematic DVT screening in COVID-19 patients is warranted.

\section{Introduction}

Recent publications suggest a high incidence of venous thromboembolism (VTE) in Coronavirus disease 2019 (COVID-19) patients hospitalized in intensive care units (ICU), occurring despite routine pharmacological thromboprophylaxis [1-3]. This thrombotic profile is associated with a marked systemic activation of coagulation and cumulative VTE risk factors (obesity, immobilization, inflammation, etc.) [4]. Occurrence of VTE correlates with a more severe disease course, with a notably 5 -fold higher risk of all cause death in patients admitted to ICU [2]. This led international societies to recommend individualized thromboprophylaxis regimens for in-hospital COVID-19 patients, 
with higher level prophylaxis for the most-at-risks, even in the absence of randomized evidence [5, 6]. Prevalence of symptomatic deep vein thrombosis (DVT) in ICU patients seems to be low [2,7], but high rates of asymptomatic DVT have been reported using a systematic screening strategy in this population [8]. In contrast, little is known about the true prevalence of VTE in less severe COVID-19 patients admitted to general wards. Precise knowledge of the epidemiology of VTE in this setting is important for decision making with regards to intensity of thromboprophylaxis. We report our experience of early systematic assessment of VTE using complete doppler ultrasound (CDU) in a general ward unit of a French tertiary care university hospital.

\section{Methods}

From the beginning of April 2020, a CDU was routinely performed upon admission as a standard of care for COVID-19 patients admitted in our general ward, irrespective of VTE risk factors or D-dimer level. We retrospectively reviewed the charts of 42 patients who benefited from systematic DVT screening with CDU from April 8th to May 12th 2020 in our academic hospital (Avicenne University Hospital, Bobigny, France). We did not include patients transferred from ICU before CDU was performed. COVID-19 diagnostic was confirmed by RT-PCR results for SARS-CoV-2 by nasopharyngeal swab. When RT-PCR was negative, and given its low sensitivity [9], the patient was also adjudicated as having COVID-19 when CT-scan images were considered typical by a senior chest radiologist with compatible clinical data and no alternative diagnosis. A CDU from abdomen to ankle with Doppler waveforms and images was performed for each patient by two independent experimented specialists in vascular medicine. If PE was suspected, patients underwent a CTPA to confirm the diagnosis. Anticoagulation was left to the discretion of the treating physician, who was trained to a recent proposal from a French reference group in haemostasis (GIHP/GFHT) [10], suggesting intermediate prophylactic doses for obese patients or low risk ICU patients, and therapeutic doses for those with marked coagulation activation or high risk ICU patients. Demographic, clinical, laboratory, treatment, CT-scan, CDU and outcome data for patients with or without DVT were extracted from electronic medical records until May 18th 2020. Continuous variables were expressed as median (interquartile range) and categorical variables as numbers (percentages). Continuous variables were compared by the Student test or the Wilcoxon rank sum test and categorical variables by the Chi-square test or the Fisher's exact test when appropriate. Analyses were performed in R, version 3.6.2. The local ethics committee of Avicenne University Hospital approved this retrospective study and waived the need of informed consent.

\section{Results}

We extracted data from 42 patients admitted to our general ward from April 8th to May 12th 2020 with proven COVID-19 pneumonia who underwent a systematic lower limb CDU. Relevant clinical and biological data are summarized in Table 1. Mean age was 65 (SD: 19) and 23 (55\%) patients were male. Median body mass index (BMI) was $28 \mathrm{~kg} / \mathrm{m}^{2}$ (IQR: $24-32$ ). CDU was performed at a median 4 days (IQR: $2-6$ ) after admission and at a median 11 days (IQR: $8-15.7$ ) after COVID-19 symptoms onset. This strategy identified 8 (19\%) patients with asymptomatic DVT. DVT was bilateral in 4/8 cases, and mostly affected distal veins (7/8 cases). More than one vein was thrombosed in $5 / 8$ cases. An angio-scanner was done in $54.8 \%$ cases, and specifically in $5 / 8(62.5 \%)$ patients with asymptomatic DVT. A pulmonary embolism was detected in 4 cases $(9.5 \%)$, but only one case was associated with a (proximal) asymptomatic DVT. In our study, 59.5\% patients were on standard regimen thromboprophylaxis, $23.8 \%$ on intermediate-dosage thromboprophylaxis and $16.7 \%$ on therapeutic-dose anticoagulation with no significant difference between patients with or without DVT. No patients benefited from pharmacological prophylaxis at home before admission. At the end of data collection (May 18th), 2 (4.8\%) patients died, 3 (7.1\%) were admitted in ICU, 3 (7.1\%) were still hospitalized and 34 (81\%) were discharged alive. Compared to patients without DVT, patients with DVT were older $(77.7 \pm 15.2$ years vs $61.5 \pm 19.0$ years, $p=0.02$ ) and might experience poorer outcomes with less chance of being discharged alive (Table 1). Other demographics, comorbidities or clinical manifestations were similar in COVID-19 patients with and without VTE. No significant differences were observed with regards to the levels of inflammatory or coagulation markers (highest levels before CDU) in the two groups.

\section{Discussion}

In this study we found that $19 \%$ of unselected COVID19 patients hospitalized in general wards of a tertiary care center developed asymptomatic DVT of the legs at a median time of 11 days (IQR: 8-15.7) after symptoms onset and 4 days (IQR: 2-6) after admission despite systematic in-hospital thromboprophylaxis. Four cases of symptomatic PE also occurred, leading to a $26 \%$ rate of VTE in our population. This rate is higher than usually encountered in hospitalized patients without COVID 19 infection (e.g., $5.5 \%$ before day 14 in the Medenox study 
Table 1 Characteristics of included patients

\begin{tabular}{|c|c|c|c|c|}
\hline & All $(n=42)$ & DVT present $(n=8)$ & DVT absent $(\mathrm{n}=34)$ & $\mathrm{p}$ \\
\hline Age (year) & $64.6+19.3$ & $77.7+15.2$ & $61.5+19.0$ & $0.02 *$ \\
\hline Male sex, no. (\%) & $23(54.8)$ & $4(50)$ & $19(55.9)$ & 1 \\
\hline BMI $\left(\mathrm{kg} / \mathrm{m}^{2}\right)$ & $28(23.9-32)$ & $21.9(19.4-26.9)$ & $28(23.9-32)$ & 0.16 \\
\hline Median time (IQR) from hospitalization to CDU (days) & $4(2-6)$ & $6(4.2-8.2)$ & $3(2-6)$ & 0.16 \\
\hline Median time (IQR) from symptom onset to CDU (days) & $11(8-15.7)$ & $14(9.5-26.2)$ & $10.5(7.2-15)$ & 0.16 \\
\hline \multicolumn{5}{|l|}{ Comorbidities, no.(\%) } \\
\hline Hypertension & $20(47.6)$ & $6(75)$ & $14(41.2)$ & 0.12 \\
\hline Diabetes & $13(31)$ & $3(37.5)$ & $10(29.4)$ & 0.69 \\
\hline Cardiovascular dieases & $7(16.7)$ & $2(25)$ & $5(14.7)$ & 0.6 \\
\hline Current smoking & $5(11.9)$ & $1(12.5)$ & $4(11.8)$ & 1 \\
\hline Active cancer & $3(7.1)$ & $1(12.5)$ & $2(5.9)$ & 0.48 \\
\hline RT-PCR positive for COVID-19, no. (\%) & $33(78.6)$ & $5(62.5)$ & $28(82.4)$ & 0.3 \\
\hline \multicolumn{5}{|l|}{ Stage of imaging, no.(\%) } \\
\hline Mild & $7(16.7)$ & $1(12.5)$ & $6(17.6)$ & \multirow[t]{4}{*}{0.56} \\
\hline Moderate & $23(54.8)$ & $4(50)$ & $19(55.9)$ & \\
\hline Severe & $8(19)$ & $3(37.5)$ & $5(14.7)$ & \\
\hline Missing data & $4(9.5)$ & $0(0)$ & $4(11.8)$ & \\
\hline \multicolumn{5}{|l|}{ Anticoagulation, no. $(\%)$} \\
\hline Usual prophylactic doses & $25(59.5)$ & $4(50)$ & $21(61.8)$ & \multirow[t]{3}{*}{0.26} \\
\hline Intermediate prophylactic doses & $10(23.8)$ & $1(12.5)$ & $9(26.5)$ & \\
\hline Therapeutic doses & $7(16.7)$ & $3(37.5)$ & $4(11.8)$ & \\
\hline \multicolumn{5}{|l|}{ DVT, no. (\%) } \\
\hline Proximal & - & $1(12.5)$ & - & \multirow[t]{10}{*}{-} \\
\hline Distal & - & $7(87.5)$ & - & \\
\hline 1 vein affected & - & $3(37.5)$ & - & \\
\hline 3 veins affected & - & $3(37.5)$ & - & \\
\hline 4 veins affected & - & $1(12.5)$ & - & \\
\hline 5 veins affected & - & $1(12.5)$ & - & \\
\hline Femoro-popliteal vein & - & $1(12.5)$ & - & \\
\hline Peroneal vein & - & $6(75)$ & - & \\
\hline Posterior tibial vein & - & $3(37.5)$ & - & \\
\hline Soleus vein & - & $5(62.5)$ & - & \\
\hline \multicolumn{5}{|l|}{ PE, no. (\%) } \\
\hline All & $4(9.5)$ & $1(12.5)$ & $3(8.8)$ & \multirow[t]{5}{*}{-} \\
\hline Right sided & $3(75)$ & 1 & 2 & \\
\hline Bilateral & $2(50)$ & 0 & 2 & \\
\hline Proximal & $0(0)$ & 0 & 0 & \\
\hline Segmental or sub-segmental & $4(100)$ & 1 & 3 & \\
\hline \multicolumn{5}{|l|}{ Outcome no. (\%) } \\
\hline Hospitalisation & $3(7.1)$ & $2(25)$ & $1(2.9)$ & \multirow[t]{4}{*}{$0.009^{*}$} \\
\hline Discharged & $34(81)$ & $4(50)$ & $30(88.2)$ & \\
\hline ICU & $3(7.1)$ & $0(0)$ & $3(8.8)$ & \\
\hline Died & $2(4.8)$ & $2(25)$ & $0(0)$ & \\
\hline D-dimer $(\mu \mathrm{g} / \mathrm{ml})$ & $1414(951-3946)$ & $1988(1374-6453)$ & $1253(873-3432)$ & 0.11 \\
\hline Fibrinogen $(\mathrm{g} / \mathrm{l})$ & $5.70(4.87-6.68)$ & $6.06(5.10-6.49)$ & $5.60(4.82-6.76)$ & 0.73 \\
\hline $\mathrm{CRP}(\mathrm{mg} / \mathrm{l})$ & $85(45-121)$ & $90(50-138.8)$ & $85(45-121)$ & 0.99 \\
\hline Prothrombin ratio (\%) & $79(70-84.75)$ & $80.5(77-82.5)$ & $79(67-88)$ & 0.39 \\
\hline APTT ratio & $1.100(1.008-1.192)$ & $1.100(1.008-1.192)$ & $1.100(1.015-1.160)$ & 0.97 \\
\hline Interleukin-6 (mg/l) & $42.75(20.95-100.35)$ & $216.8(216.8-216.8)$ & $38.50(19.70-81.15)$ & 0.2 \\
\hline Leukocyte count (per $\mathrm{mm}^{3}$ ) & $7.65(6.10-12.4)$ & $8.65(6.15-13.62)$ & $7.65(6.10-10.60)$ & 0.61 \\
\hline
\end{tabular}


Table 1 (continued)

\begin{tabular}{|c|c|c|c|c|}
\hline & All $(n=42)$ & DVT present $(\mathrm{n}=8)$ & DVT absent $(n=34)$ & $\mathrm{p}$ \\
\hline Hemoglobin (g/dl) & $12(10.3-12.8)$ & $11.5(10.6-12.2)$ & $12.2(10.3-13.2)$ & 0.36 \\
\hline Platelet count $\left(10^{9} / 1\right)$ & $258(166-395)$ & $183(158-285)$ & $275(170-318)$ & 0.21 \\
\hline Lymphocyte count (per $\mathrm{mm}^{3}$ ) & $0.89(0.66-1.22)$ & $0.8(0.53-1)$ & $0.89(0.7-1.01)$ & 0.33 \\
\hline Albumine $(\mathrm{g} / \mathrm{l})$ & $27(23-32)$ & $25.5(23.75-30)$ & $28(23-32.5)$ & 0.84 \\
\hline $\mathrm{SPO}_{2}(\%)$ & $92.5(90-95)$ & $89(87-93)$ & $93(90-95)$ & 0.17 \\
\hline $\mathrm{PaO}_{2}(\mathrm{mmHg})$ & $73(63-82)$ & $70(58-84)$ & $73(63-81)$ & 0.84 \\
\hline
\end{tabular}

$* \mathrm{p}<0.05$

[11], even if recent studies showed lower rates of asymptomatic DVT in this population [12]), emphasizing the severe prothrombotic profile of COVID-19 patients. Nevertheless, we cannot rule out a role of bedrest without thromboprophylaxis before admission in this high-risk population. Recent retrospective studies without systematic screening for DVT report a lower rate of symptomatic DVT in anticoagulated COVID-19 patients admitted to ICU (3\% in Klok et al. [2], 2\% in Lodigiani et al. [7]) or to general wards (1.2\% in Lodgiani et al. [7]) but likely underestimate the real rates of VTE. Three studies report systematic CDU assessment in ICU patients: In a Chinese cohort of 81 patients without prophylactic anticoagulation, asymptomatic DVT was diagnosed in $25 \%$ of cases [1]. In another two recent studies of anticoagulated ICU COVID19 patients, $69 \%$ of 26 patients [8] and $31 \%$ of 75 patients [9] were found positive for DVT using systematic screening. A few recent publications report conflicting results as regards to systematic screening for DVT in general wards: In two of them, the authors failed to detect any DVT out of 17 [3] and 64 [13] COVID-19 patients. If a CDU was performed was nevertheless not mentioned in these studies, and as only one proximal DVT was found in our work, compression ultrasound limited to proximal veins may be of limited relevance in this context. In another retrospective study, $22.5 \%$ out of 71 anticoagulated COVID-19 patients developed DVT, but symptomatic patients were included and CDU was performed at discharge (median after admission: 13 days) for asymptomatic patients [14]. In a recent prospective work, incidental DVT was diagnosed in $14.7 \%$ of 156 patients hospitalized in general wards at a median 9 days of hospitalization, but this study only focused on high risk patients with initial D-dimer level exceeding $1000 \mathrm{ng} / \mathrm{ml}$ [15]. Our study shed a new light on the epidemiology of VTE in COVID-19 patients as it showed that asymptomatic DVT occurs early in the course of the disease, and can also affect patients with mild activation of coagulation.

Our retrospective data may suggest poorer outcomes in COVID-19 patients with DVT, in line with previous publications especially in ICU $[1,3,7]$. Only one patient with asymptomatic (proximal) DVT suffered from PE in our cohort. Asymptomatic DVT may be thus be considered as a hallmark of clinical severity rather than a high risk of lethal PE in COVID-19 patients. On the other hand, the diagnosis of asymptomatic DVT led to initiation of therapeutic anticoagulation, which may have prevented the occurrence of PE in most cases. The high prevalence of DVT in our cohort argues against the unique in situ immuno-thrombosis hypothesis for PE in COVID-19 pneumonia, with a likely role of conventional thromboembolic origin $[2,13]$.

We acknowledged the preliminary nature of these findings: Our study is limited by its small sample size, the lack of a control group and its retrospective and single-center nature. A prospective study is needed to investigate the true occurrence and fatality rates of VTE in unselected anticoagulated COVID-19 patients. However the high prevalence of asymptomatic DVT in our cohort advocate for a more systematic screening for DVT in the first days after admission and for more individualized assessment of thromboprophylaxis regimen in general wards.

Author's contribution SLJ designed the study, collected data and wrote the manuscript. JS, RB, FF, UW, RD collected data and wrote the manuscript. FM and $\mathrm{CP}$ performed the CDU.

Funding None.

\section{Compliance with ethical standards}

Conflict of interest The authors declare that they have no conflicts of interest.

Ethical approval This retrospective chart review study involving human participants was in accordance with the ethical standards of the institutional and national research committee and with the 1964 Helsinki Declaration and its later amendments or comparable ethical standards. 


\section{References}

1. Cui S, Chen S, Li X, Liu S, Wang F (2020) Prevalence of venous thromboembolism in patients with severe novel coronavirus pneumonia. J Thromb Haemost. https://doi.org/10.1111/jth.14830

2. Klok FA, Kruip MJHA, van der Meer NJM, Arbous MS, Gommers D, Kant KM, Kaptein FHJ, van Paassen J, Stals MAM, Huisman MV, Endeman H (2020) Confirmation of the high cumulative incidence of thrombotic complications in critically ill ICU patients with COVID-19: an updated analysis. Thromb Res. https://doi. org/10.1016/j.thromres.2020.04.041

3. Middeldorp S, Coppens M, van Haaps TF, Foppen M, Vlaar AP, Müller MCA, Bouman CCS, Beenen LFM, Kootte RS, Heijmans J, Smits LP, Bonta PI, van Es N (2020) Incidence of venous thromboembolism in hospitalized patients with COVID-19. J Thromb Haemost. https://doi.org/10.1111/jth.14888

4. Connors JM, Levy JH (2020) COVID-19 and its implications for thrombosis and anticoagulation. Blood. https://doi.org/10.1182/ blood.2020006000

5. Bikdeli B, Madhavan MV, Jimenez D, Chuich T, Dreyfus I, Driggin E, Nigoghossian C, Ageno W, Madjid M, Guo Y, Tang LV, Hu Y, Giri J, Cushman M, Quéré I, Dimakakos EP, Gibson CM, Lippi G, Favaloro EJ, Fareed J, Caprini JA, Tafur AJ, Burton JR, Francese DP, Wang EY, Falanga A, McLintock C, Hunt BJ, Spyropoulos AC, Barnes GD, Eikelboom JW, Weinberg I, Schulman S, Carrier M, Piazza G, Beckman JA, Steg PG, Stone GW, Rosenkranz S, Goldhaber SZ, Parikh SA, Monreal M, Krumholz HM, Konstantinides SV, Weitz JI, Lip GYH (2020) COVID-19 and thrombotic or thromboembolic disease: implications for prevention, antithrombotic therapy, and follow-up. J Am Coll Cardiol. https://doi.org/10.1016/j.jacc.2020.04.031

6. Thachil J, Tang N, Gando S, Falanga A, Cattaneo M, Levi M, Clark C, Iba T (2020) ISTH interim guidance on recognition and management of coagulopathy in COVID-19. J Thromb Haemost 18(5):1023-1026. https://doi.org/10.1111/jth.14810

7. Lodigiani C, Iapichino G, Carenzo L, Cecconi M, Ferrazzi P, Sebastian T, Kucher N, Studt JD, Sacco C, Alexia B, Sandri MT, Barco S, Humanitas COVID-19 Task Force (2020) Venous and arterial thromboembolic complications in COVID-19 patients admitted to an academic hospital in Milan, Italy. Thromb Res 191:9-14. https://doi.org/10.1016/j.thromres.2020.04.024

8. Llitjos JF, Leclerc M, Chochois C, Monsallier JM, Ramakers M, Auvray M, Merouani K (2020) High incidence of venous thromboembolic events in anticoagulated severe COVID-19 patients. J Thromb Haemost. https://doi.org/10.1111/jth.14869

9. Wang W, Xu Y, Gao R, Lu R, Han K, Wu G, Tan W (2020) Detection of SARS-CoV-2 in different types of clinical specimens. JAMA 323(18):1843-1844. https://doi.org/10.1001/ jama.2020.3786

10. Susen S, Tacquard CA, Godon A, Mansour A, Garrigue D, Nguyen P, Godier A, Testa S, Albaladejo P, Gruel Y, au nom du GIHP et du GFHT (2020) Traitement anticoagulant pour la prévention du risque thrombotique chez un patient hospitalisé avec COVID-19 et surveillance de l'hémostase. Propositions du GIHP et du GFHT. https://site.geht.org/actu/propositions-du-gfht-gihppour-le-traitement-anticoagulant-pour-la-prevention-du-risqu e-thrombotique-chez-un-patient-hospitalise-avec-covid-19/. Accessed 3 Apr 2020

11. Alikhan R, Cohen AT, Combe S, Samama MM, Desjardins L, Eldor A, Janbon C, Leizorovicz A, Olsson CG, Turpie AG, MEDENOX Study (2004) Risk factors for venous thromboembolism in hospitalized patients with acute medical illness: analysis of the MEDENOX Study. Arch Intern Med 164(9):963-968. https ://doi.org/10.1001/archinte.164.9.963

12. Loffredo L, Arienti V, Vidili G, Cogliati C, Battaglia S, Perri L, Di Giulio R, Bernardini S, Summa ML, Sciacqua A, Perticone F, Boddi M, Di Minno G, Lodigiani C, Pietrangelo A, Farcomeni A, Violi F, AURELIO Study Group (2019) Low rate of intrahospital deep venous thrombosis in acutely Ill medical patients: results from the AURELIO study. Mayo Clin Proc 94(1):37-43. https:// doi.org/10.1016/j.mayocp.2018.07.020

13. Cattaneo M, Bertinato EM, Birocchi S, Brizio C, Malavolta D, Manzoni M, Muscarella G, Orlandi M (2020) Pulmonary embolism or pulmonary thrombosis in COVID-19? Is the recommendation to use high-dose heparin for thromboprophylaxis justified? Thromb Haemost. https://doi.org/10.1055/s-0040-1712097

14. Artifoni M, Danic G, Gautier G, Gicquel P, Boutoille D, Raffi F, Néel A, Lecomte R (2020) Systematic assessment of venous thromboembolism in COVID-19 patientsreceiving thromboprophylaxis: incidence and role of D-dimer as predictivefactors. J Thromb Thrombolysis 25:1-6. https://doi.org/10.1007/s1123 9-020-02146-z

15. Demelo-Rodríguez P, Cervilla-Muñoz E, Ordieres-Ortega L, Parra-Virto A, Toledano-Macías M, Toledo-Samaniego N, GarcíaGarcía A, García-Fernández-BravoI JZ, de-Miguel-Diez J, Álvarez-Sala-Walther LA, Del-Toro-Cervera J, Galeano-Valle F (2020) Incidence of asymptomatic deep vein thrombosis in patients with COVID-19 pneumonia and elevated D-dimer levels. Thromb Res 192:23-26. https://doi.org/10.1016/j.thromres.2020.05.018

Publisher's Note Springer Nature remains neutral with regard to jurisdictional claims in published maps and institutional affiliations. 